\title{
The use of virtual patients in medical education
}

\author{
Tip Eğitiminde sanal hasta kullanımı
}

Özlem MIDIK, Mehtap KARTAL

\begin{abstract}
The use of simulations in medical education depends on the interest of the academic institutions and the educators, on technological developments, on infrastructure, on the resources of the medical faculties and on the integration into medical curricula. Virtual patient simulations involving high-techology, emerge as one of today's most popular topics in medical education.
\end{abstract}

In this review, a simulation, "virtual patient", is studied under the main headings concerning its description, essential features, its use and its future in medical education.

Keywords: Virtual patient, Virtual systems, Medical education, Computer based cases

\section{ÖZET}

Simülasyon uygulamalarının kullanımı, kurumun ve eğiticilerin ilgisine, teknolojinin gelişimine, fakültelerin alt yap1 ve olanaklarına ve programın müfredata entegrasyonuna bağlı olarak gelişir. İleri teknoloji içeren sanal hasta simülasyonları ise günümüzün en popüler konularından biri olarak karşımıza çıkmaktadır.

Bu derlemede bir simülasyon tipi olan 'sanal hasta' tanımı, temel özellikleri, tıp eğitiminde kullanımı ve geleceği irdelenecektir.

Anahtar kelimeler: Sanal hasta, Sanal sistemler, Tıp eğitimi, Bilgisayar tabanlı vakalar

Özlem Midık (ه)

Department of Medical Education, School of Medicine, Ondokuz Mayls University, Samsun, Turkey

e-mail:dromidik@gmail.com

Mehtap Kartal

Department of Family Medicine, School of Medicine, Dokuz Eylül University, Izmir, Turkey

Submitted/Gönderilme: 13.01.2015

Accepted/Kabul: 27.03.2015

\section{Introduction}

The purpose of medical education is to educate physicians so that everyone can enjoy a healthy life [1]. In the light of that aim the educated physician is expected to possess a large number of skills. This expectation requires that medical education be high-quality and scientific and also constantly self-renewing.

Medical faculties today define themselves, not on the basis of the systems, but of the educational strategies they use, and adopt a pluralistic approach. The pluralistic approach, which goes back to the philosophy of science of Feyerabend [2], is reflected in medical education due to the hypotheses set out below.

- No theory is by itself sufficient to explain learning and teaching

- No behavior or cognitive affective attribute can be taught through a single theory or method.

- Different means should be employed for each individual to learn the same behavior or attribute.

- Different strategies, methods or reasoning procedures must be used when the level or nature of behavior changes.

- Behaviors and learning are more permanent when several activities are employed together [2,3].

The reflection of pluralism in medical education is seen in curriculum planning and in the components of strategies, methods, climates and testing in application and evaluation. The educational method contains sufficient variety to permit a multi-method to the curriculum. This includes class teaching, problem based learning sessions, team work, bedside training, training outpatient clinics and operating rooms and skills training. The newest approach in terms of education management is simulation-based training. Simulation is defined as the imitation of tasks, relationships, phenomena, equipment, behavior or some cognitive 
activities that are actually present in reality.

Various kinds of simulation tools are used in medical education. One of the most popular subjects today is patient simulation using high-tech methods.

This review examines the definition, basic features, use in medical education and future of one type of simulation the 'virtual patient' (VP).

\section{What is a virtual patient?}

A virtual patient (VP) is defined as a special type of computer program used in medical education or testing, that simulates clinical scenarios in real life and in which learners emulate health professionals in taking histories, performing physical examinations and deciding on diagnosis and treatment [4]. In one sense, the VP is an online, interactive computer simulation of an encounter with a patient [5].

\section{How did the concept of the virtual patient appear?}

The development and use of the a VP is nothing new. Computer-based training simulations of patient encounters were first developed in the 1960s [6]. These were described as 'case-based learning systems, computer-assisted simulations, interactive patients and patient simulations,' and as 'virtual patients' after 2005 [7]. For reasons such as high cost, a low level of expertise, technical and design limitations, limited evidence of effectiveness and, finally, for cultural reasons, their spread has not been as rapid as was once expected [8]. The growth in their use in recent years has been attributed to the lowering of costs and the fact they can be created, redesigned and shared between institutions [9].

\section{Why was there a need for virtual patients?}

Complexity, uncertainty and inconsistencies in the field of healthcare are increasing. The concept of hospitalization has changed due to economic pressures, and lengths of hospitalization have been shortened. This has led to a more opportunistic educational environment in which the patient profile is regarded as a constant variable. Today's medical training process reduces interaction between instructor, patient and student, restricts experience-based learning and does not allow for patient encounters [5]. Yet the minimum skills required of newly graduated physicians are increasing all the time in terms of numbers and levels.

Although diagnostic errors are frequently thought to be associated with an inadequate collection for information, such errors in fact derive from faulty interpretations and deficiencies in synthesis and reasoning, in other words from cognitive mistakes. This is attributed to students not encountering sufficient cases and to their lack of experience [4]. Although physicians' medical knowledge grows, uncertainty in taking medical decisions increases and insufficient time is set aside for training. Different clinical pathways are frequently required for the acquisition of reliable and effective knowledge.

Research shows that clinical reasoning skills of students develop most when meeting patients, encountering and actively solving problems and, most importantly, through adequate feedback [4]. Meeting the patient is important for the acquision of core knowledge. Medical practice is a field involving interventional techniques, the use of which is increasing. However, students have increasingly less opportunity to learn patient care and interventional techniques. Physical simulation is not always available, although simulated and/or standardized patients make this partly possible [6]. One of the main problems in medical education, despite the high expectations from graduate physicians, is the lack of sufficient resources such as materials, personnel and opportunities for meeting patients during training. In particular, despite the rise in student numbers, the low number of instructors in some countries is striking. This is described as a manpower crisis in subSaharan African countries such as Malawi [10].

Simulation is a potential solution that can partly ease the problem(s) described above. Accreditation bodies explicitly state that if no means are available in the clinical environment then students need to receive simulated experiences [6].

\section{How are virtual patients used in medical education?}

VP procedures are used to develop four skills in learningteaching procedures and evaluations in the medical education trilogy of pre-graduation, post-graduation and ongoing professional development [11-15].

\section{Clinical reasoning, problem-solving}

Clinical reasoning is the integration and application of knowledge acquired from various sources within a diagnostic and therapeutic management plan. Although clinical reasoning is regarded as a general skill, it is in fact a case-dependent one. For example, reasoning regarding headache cannot always be applied to abdominal pain. Specialists frequently make use of patterns and disease scripts in the clinical reasoning process. However, more cases are required for new learners [16]. 
A VP is a procedure that bestows experience by offering various options through different cases [4]. A VP provides an opportunity to acquire treatment management skills through clinical reasoning and problem solving, reduces the numbers and effects of medical errors and thus contributes to patient safety [5]. VP procedures have been shown to be the best means of acquiring these skills at a superior level [8].

2. Core knowledge acquisition

Some VPs are designed for the purpose of improving conceptual knowledge and illuminating the basic principles underlying medical procedures. However, there are those who maintain that VP use is not the best means of teaching and facilitating core knowledge and who believe that dealing with basic subjects through traditional educational methods before using VPs will reduce the cognitive burden that may arise during VP applications [4].

\section{Skills acquisition}

A VP can be used in teaching history taking, physical examination, communication and procedural skills. However, the technique may be inadequate when it comes to understanding and expressing basic principles (such as diagnosing a mitral stenosis murmur or asking questions appropriate to a dyspneic subject), to the application of effective skills (such as knowing when to perform cardiac examination or performing appropriate auscultation) or learning empathy-building skills. Simulated or standardized patients are individuals who are selected and trained to portray a patient accurately and consistently [17]. Simulated/ standardized patient use is thought to be more appropriate in the acquisition of such skills [4].

4. Affective characteristic development

Although simulated/standardized patients are recommended in the development of affective characteristics such as student interest, motivation, attitude and academic self-concept, some studies have shown that VP use is beneficial in the acquisition of professional competence and objectives concerning ethics and the law $[12,14,18,19]$.

\section{What are the features of the vitual patient system?}

A VP differs from other form of simulation. The VP system is one of the high fidelity simulation forms, and requires special equipment [4].VPs are processed on the computer screen by way of clinical scenarios. The computer provides the patient responses and the requisite information. The learner communicates with the patient (the computer) by writing, selection or in some cases by speaking. During this process, the learner has to develop a diagnostic and management plan. There is considerable scope for variation within this program. These variations have different effects on learning and evaluation, but the case itself represents the most important structure. Case selection and arrangement may be more important than the technical case details. Feedback is very important; it permits the development of such cognitive attributes as recall, attention, reasoning and problem solving [4].

Standard web and multimedia tools are used for VP. These are frequently installed in special systems in which both the writing process and the resulting VP applications are revealed. These systems reflect the designers' norms, values and concepts together with any technology employed [4].

There is no clear answer to the question of which VP design is more effective for learning, and there is no standard setting out which characteristics the VP should possess. Strategies determined for VP applications include encouraging clinical reasoning, developing teaching cases, improving learning through simulation and designing effective multimedia tools for cognitive learning. These strategies certainly need to be present in VP applications, although it is unclear how these affect student learning [20].

Techniques recommended for effective VP designs include:

- Asking open-ended questions,

- Providing single-sentence summaries of patient problems,

- Asking questions to elicit characteristics for differentiating or testing diagnostic hypotheses,

- Drawing early conclusions for a differential diagnosis,

- Prioritizing diagnoses,

- Encouraging the student to compare diagnostic hypotheses based on genuine clinical data,

- Showing relatively diverse diagnostic possibilities and

- Showing typical presentations of different diagnostic hypotheses.

Case characteristics should be relevant, realistic, interconnected, demanding and instructive [21-23].

There are numerous variations including one or more characteristics in VP applications. Characteristics and basic questions for VP variations are shown in Table I. 
Table I: Characteristics and basic questions for VP variations $[4,20]$

Interactivity-What kind of information is included in the case?

Requesting and providing clinical information - how do learners elicit and interpret information? (in the form of text, sound or images)

Case flow - does the case flow change? For example, does the case flow change depending on the learner's decisions or by chance?

Diagnostic information - Is the diagnosis known from the outset or not?

Case organization - (diagnosis, difficulty, number) selected or consecutive?

Feedback and instruction-how and when do these appear?

Instructional development - What kind of teaching strategies such as listing differentiating characteristics, requesting tests or differentiating different cases are involved?

Learner characteristics - what is the learner's level and existing clinical knowledge?

Learner collaboration - does the learner work alone or in a group? Curriculum integration - Is it part of the compulsory curriculum or an elective?

Evaluation - how and for what purpose is evaluation used?

Case development and maintenance - how were and are cases developed?

VP typologies employing different systems are currently in use. The majority of these have been developed on the basis of international cooperation in the scope of projects. One example of this is the-VIP Project [24] which is intended to investigate standards in health and medical education, comply with technical standards and make it possible to share the VP content. Using four different systems and more than 300 cases, e-VIP permits material exchange between nine institutions (Great Britain Warwick, Coventry and St George's Hospital; Sweden's Karolinska Institutet; Germany Heidelberg, Witten/Herdecke and Ludwig-Maximilians; The Netherlands Maastricht; Poland Jagiellonski and Romanian universities) [7]. The computer programs include: CASUS [25], Munich Ludwig-Maximilians University; CAMPUS [26], HeilderbergUniversity OpenLabyrinth (27), Edinburgh UniversityWeb-SP (28), Karolinska Institutet.

Other systems and approaches include Tufts, Pittsburg, New York University, The International Virtual Medical School and Decision Simulation $[7,29,30]$.

\section{What is the evidence regarding virtual patient?}

Research into VP in medical education constitutes evidence in the following three spheres:

\section{Satisfaction with VP}

VP is popular with students because of its independence, compatibility with student programs, the contribution it makes to the cognitive case library and its stress-free environment. However, students also add that it cannot replace real patients. They also appreciate its data collection process, more/less demanding options, its provision of developments that respond to the student's actions and the presence of feedback. Students report that authenticity, case type and computer presentation (including video and with realistic dialogues and fluent speech) also contribute to case realism [31].

The VP system requires technological sufficiency and is difficult for instructors. Some instructors suggest that these applications make them ineffective [32].

2 The effect of VP on learning

- Evaluations based on post-test

Studies involving procedures without pre-tests have assessed students' knowledge acquisition, and evidence has emerged that VP facilitates learning [33-35].

- Comparative evaluations

Many comparative evaluations have been performed with simulated patient procedures. Studies have reported that VP procedures facilitate the student's learning and grasp of the technical aspects of medical interviews. On the other hand, simulated patient procedures have been found to be more effective in terms of exhibition of affective skills [19].

One study comparing VP with written cases reported that students prefer VP applications to written versions [36].

In a two-group comparative study of students on internal diseases internships, Botezatu et al. reported that VP provided better long-term memorization than traditional learning methods [36].

\section{VP designs}

There is no guide to the design and application of VP, although research into VP design and application has increased in recent years.

\section{- Studies comparing case formats}

Studies by Friedman and Bearman may be regarded as some of the earliest research. In 1991, Friedman compared three case formats, pedagogic, problem solving and highfidelity. The pedagogic format achieved greater success in post-test, but the other formats produced more hypotheses directed toward reasoning. Bearman's 2001 study reported that a narrative approach, in which series of effects over time were set out around a consistent main theme, was more effective in students' acquisition of communication 
skills than the problem solving approach involving a case needing to be solved. Bearman's 2003 study reported that the problem solving format led to greater negative emotions, such as anger, in students [32,37].

\section{- Studies comparing menus}

One study compared the CAMPUS classic and cardbased types in a problem solving format. The CAMPUS classic type is a simulative mode of presentation containing relatively free navigation and an authentic web-based interface (in these an image of an examining room is shown behind the patient and in which students' movements are shown in graphic form, so that those parts of the body that are examined are being shown in color). This format is predominantly characterized by long question menus. The long menu lists consist of appropriate, likely related options for students to choose between. The capacity of the lists is in the region of 8000 items. Students can also access free text. These questions permit automatic feedback. The CAMPUS card-based type is a presentation model containing a short menu of questions without graphic support with a previously determined task flow and web-based interface. The study results showed that students found the classic type with a long menu mode more demanding but more motivating, and much preferred it due to its revelation of gaps in knowledge and its being intended to fill these [7].

Jäger et al. reported that brief VP cases, having a mean case study time of $15 \mathrm{~min}$ and important take-home messages in the design, were more effective on student outputs [38].

- Studies concerning the origin of virtual patient data

One study investigating the source of cases necessary for VP applications revealed that electronic health records are frequently taken from hospital computer systems and that genuine patient data and the experiences of clinical trainers are often employed together. Requirements of these applications include that they should be easy to obtain, the anonymity of data, and that they should reflect the current reality, together with deficient information [39].

- Studies regarding its place in the curriculum

Studies have shown that designs that are associated with seminars, courses and corresponding tests [40], that are balanced [41] and appropriately integrated into the curriculum [42] all motivate students. Edelbring emphasized the importance of assessing VP-based activities not as separate phenomena but as an integrated whole together with other educational activities [42].

- Studies concerning individual or group applications

VP applications are suited to individualized learning and assessment. However, students prefer group work in terms of rectifying their deficiencies, increasing motivation and observing different approaches. Kühne-Eversmann submitted evidence that working with a partner activates the student, increases knowledge levels, improves reasoning abilities and elicits greater discussion about approaches to patient management $[31,38,43]$. Jäger et al. revealed that students with high levels of preliminary knowledge who work with a partner are more successful and that short VP cases are more effective [38].

\section{The future of virtual patient applications}

Trainers, clinicians and researchers emphasize the pedagogic value and significant effects of VP. They report that while VPs cannot replace real patients they can be employed as an assistant tool for improving clinical reasoning and problem solving skills in particular in medical education.

International information is the most important element in helping to spread VP applications, in ease of accessibility and in establishing norms for the field. It is predicted that the time spent on VP design will gradually decrease and that design will become easier. VP authoring systems will be developed and branching designs in which the outcomes of different decisions that can improve patient management skills will emerge. VPs will become an indispensible part of the curriculum, will be used together with other simulative tools, and three-dimensional environments including digital avatars will be seen $[5,29]$.

\section{Conclusion: The situation in Turkey and projections and recommendations for the future}

There is increasing research into simulation applications in Turkey. Simulation is occupying ever greater space in education programs, various simulation tools are being used and skills appropriate to a spiral curriculum are becoming the main element of education programs. Work is also taking place on the opening of skills laboratories in faculties as well as simulation facilities at the central level. National and international symposia and congresses are being held to increase interaction between simulation and relevant professions. However, VP applications in Turkey are still at the theoretical level.

Although VP applications are still regarded as a project involving economic burdens on faculties, one of the most important factors in the structuring and implementation of VP applications is multiple professional interaction. In particular, joint projects with computer engineering can be arranged at the local level, and this will assist with the emergence of more economical and applicable systems. 
The use of VP applications will assist faculty curricula in terms of multiple methods. It must be regarded as a factor that will enhance physicians' skills and contribute to a highquality health field. It must not be forgotten that VP systems make a great contribution to reasoning and decision-making processes, and the educational impact on students with its educational objectives, aims, means and interaction must be borne in mind when including the method in the system.

It seems not unrealistic to predict that with the advantages bestowed on multiple method use by educational programs employing VP applications, these will be increasingly more widely used in Turkey as well as in a rapidly changing world.

\section{References}

1. Sayek I, Kiper N, Odabasi O. Mezuniyet Öncesi Tıp Eğitimi Raporu 2008. Ankara: Türk Tabipleri Birliği Yayınları, 2008.

2. Doğan MP. Feyerabend ve çoğulculuk. İlim Dünyası 2012; 4: $16-26$

3. Sönmez V. Gelecekteki olası Eğitim Sistemleri. Ankara: Anı Yayınc1lik, 2008.

4. Cook DA, Triola MM. Virtual patients: a critical literature review and proposed next steps. Med Educ 2009; 43: 303-11. doi: 10.1111/j.1365-2923.2008.03286.x.

5. Poulton T, Balasubramaniam C. Virtual patients: A year of change. Med Teach 2011; 33: 933-7. doi: 10.3109/0142159X.2011.613501.

6. Ellaway RH, Davies D. Design for learning: deconstructing virtual patient activities. Med Teach 2011;33: 303-10. doi: 10.3109/0142159X.2011.550969.

7. Huwendiek S, Reichert F, Bosse HM, et al. Design principles for virtual patients: A focus group study among students. Med Educ 2009: 43: 580-8.doi: 10.1111/j.1365-2923.2009.03369.x.

8. Huang G, Reynolds R, Candler C. Virtual patient simulation at U.S. and Canadian medical schools. Acad Med 2007; 82;44651.

9. Bateman J, Allen M, Samani D, Kidd J, Davies D. Virtual patient design: exploring what works and why. A grounded theory study. Med Educ 2013; 47: 595-606. doi: 10.1111/ medu.12151.

10. Dewhurst D, Borgstein E, Grant M, Begg M. Online virtual patients- A driver for change in medical and healthcare Professional education in devoloping countries. Med Teach 2009; 31: 721-4.

11. Wood $\mathrm{E}$, Tso $\mathrm{S}$. The virtual continuity in learning programme: results. Clin Teach 2012; 9:216-21. doi: 10.1111/j.1743498X.2012.00551.x.

12. McEvoy MM, Butler B, MacCarrick G, Nicholson AJ. Virtual patients: an effective educational intervention to improve paediatric basic specialist trainee education in the management of suspected child abuse? Ir Med J 2011; 104:250-2.

13. Gunning WT, Fors UG. Virtual patients for assessment of medical student ability to integrate clinical and laboratory data to develop differential diagnoses: comparison of results of exams with/without time constraints. Med Teach 2012;34:2228. doi: 10.3109/0142159X.2012.642830.

14. Hooper CR, Jivram T, Law S, Michell A, Somasunderam A. Using virtual patients to teach medical ethics, medical law and medical professionalism. Med Teach 2012; 34:674-5. doi: 10.3109/0142159X.2012.689450.

15. Gormley GJ, McGlade, K, Thomson C, McGill M, Sun JA. Virtual surgery in general practice: Evaluation of a novel undergraduate virtual patient learning package. Med Teach 2011; 33: 522-7. doi: 10.3109/0142159X.2011.599889.

16. Norman G. Research in clinical reasoning: past history and current trends. Med Educ 2005; 39:418-27.

17. Lane JL, Slavin S, Ziv A. Simulation in medical education: A review. Simul Gaming 2001;32: 297-314.

18. Kononowicz AA, Krawczyk P, Cebula G, et al. Effects of introducing a voluntary virtual patient module to a basic life support with an automated external defibrillator course: a randomised trial. BMC Med Educ 2012; 12:41.doi: 10.1186/1472-6920-12-41.

19. Deladisma AM, Johnsen K, Raij A, et al. Medical student satisfaction using a virtual patient system to learn historytaking communication skills. Stud Health Technol Inform 2008; 132:101-5.

20. Huwendiek S, De Leng BA, Zary N, Fischer MR, Ruiz JG, Ellaway R. Towards a typology of virtual patients. Med Teach 2009; 31: 743-8.

21. Bowen JL. Educational strategies to promote clinical diagnostic reasoning. N Engl J Med 2006; 355: 2217-25.

22. Nendaz MR, Bordage G. Promoting diagnostic problem representation. Med Educ 2002; 36: 760-6.

23. Bordage G. Why did I miss the diagnosis? Some cognitive explanations and educational implications. Acad Med 1999; 74: 138-43.

24. eViP Electronic virtual patients. http://www.virtualpatients. eu. Access on 27.10.2014

25. CASUS Online. http://www.casus.net. Access on 07.11.2014

26. CAMPUS Online. http://www.campusvirtualpatients.com Access on 07.11.2014

27. OpenLabyrint. http://sourceforge.net/projects/openlabyrinth/ Access on 07.11.2014

28. Web-SP. http://www.web-sp.org/. Access on 07.11.2014

29. Benedict N. Virtual patients and problem-based learning in advanced therapeutics.Am J Pharm Educ 2010;74:143.

30. Conradi E, Kavia S, Burden D, et al. Virtual patients in a virtual world: Training paramedic students for practice. Med Teach 2009;31:713-20.

31. Cook DA, Erwin PJ, Triola MM. Computerized virtual patients in health professions education: A systematic review and meta analysis. Acad Med 2010; 85: 1589-602. doi: 10.1097/ ACM.0b013e3181edfe13 
32. Bearman M. Is virtual the same as real? Medical students' experiences of a virtual patient. Acad Med 2003;78: 538-45.

33. Kleinert HL, Fisher SB, Sanders CL, Boyd S. Improving physician assistant students' competencies in developmental disabilities using virtual patient modules. J Physician Assistant Educ 2007; 18:33-40.

34. Triola M, Feldman H, Kalet AL, et al. A randomized trial of teaching clinical skills using virtual and live standardized patients. J Gen Intern Med 2006; 21:424-9.

35. Sanders CL, Kleinert HL, Free T, Slusher I, Clevenger K, Johnson S, Boyd SE.Caring for children with intellectual and developmental disabilities: virtualpatient instruction improves students' knowledge and comfort level. J Pediatr Nurs 2007;22:457-66.

36. Botezatu M, Hult H, Fors UG. Virtual patient simulation: what do students make of it? A focus group study. BMC Med Educ 2010; 10: 91. doi: 10.1186/1472-6920-10-91

37. Bearman, M, Cesnik B, Liddell M. Random comparison of 'virtual patient'models in the context of teaching clinical communication skills. Med Educ 2001; 35: 824-32.

38. Jäger F, Riemer M, Abendroth M, Sehner S, Harendza S.
Virtual patients: the influence of case design and teamwork on students' perception and knowledge - a pilot study. BMC Med Educ 2014;14: 137. doi: 10.1186/1472-6920-14-137

39. Bloice MD, Simonic KM, Holzinger A. On the usage of health records for the design of Virtual Patients: a systematic review. BMC Med Inform Decis Mak 2013;13: 103. doi: 10.1186/1472-6947-13-103.

40. Hege I, Ropp V, Adler M, et al. Experiences with different integration strategies of case based e-learning. Med Teach 2007; 29: 791-7. doi: 10.1080/01421590701589193

41. Berman N, Fall LH, Smith S, et al. Integration strategies for using virtual patients in clinical clerkships. Acad Med 2009; 84:942-9. doi: 10.1097/ACM.0b013e3181a8c668.

42. Edelbring S, Dastmalchi M, Hult H, Lundberg IE, Dahlgren LO. Experiencing virtual patients in clinical learning: a phenomenological study. Adv Health Sci Educ Theory Pract 2011;16:331-45. doi: 10.1007/s10459-010-9265-0

43. Kühne-Eversmann L, Eversmann T, Fischer MR. Teamand case-based learning to activate participants and enhance knowledge: An evaluation of seminars in Germany. J Contin Educ Health Prof 2008; 28: 165-71. doi: 10.1002/chp.175 